\title{
The Productive Vocabulary Development in the Written Chinese of the Hong Kong Cantonese-speaking Children
}

\author{
Emily Yee Man Cheung \\ Department of Chinese, Hong Kong Institute of Education \\ Hong Kong, SAR, China \\ E-mail: ymcheun@ied.edu.hk
}

Received: April 11, $2011 \quad$ Accepted: April 22, $2011 \quad$ Published: November 1, 2011
doi:10.5539/ies.v4n4p47
URL: http://dx.doi.org/10.5539/ies.v4n4p47

\begin{abstract}
This paper reports a longitudinal investigation into the productive vocabulary development in the written Chinese of the Cantonese-speaking elementary children in Hong Kong. Data gathering took place using two vocabulary tests which selected prescriptive vocabulary from the textbooks and the 2007 Vocabulary List. The two assessment tests also included vocabulary from the two classes of words in Chinese, namely, the content and the function words. Data were collected in a senior elementary class in 2008 and 2009 respectively. The phonological, orthographical, syntactic and semantic dimensions of the children's productive vocabulary knowledge in both year four and year five were examined. The longitudinal data of these four linguistic dimensions were scored under respective conditions. The results indicate that the syntactic dimension of the function words is the weakest aspect in vocabulary growth. This may suggest that the syntactic acquisition of the function words seems to take a longer time. Furthermore, two relatively independent aspects of vocabulary knowledge, namely, the phonological-orthographical and the syntactic-semantic, emerge in the vocabulary development.
\end{abstract}

Keywords: Vocabulary acquisition, Longitudinal language development, Hong Kong Cantonese-speaking children

\section{Introduction}

Vocabulary knowledge constitutes a major aspect of language competence. It is a component of language proficiency. Vocabulary continues to expand throughout the life span (Lenneberg, 1967; Nation, 1990). It grows during infancy, early childhood, school age (age from six through twelve years), adolescent years (age from thirteen through eighteen years) and continues to develop even into adulthood (Nation, 1990; Nippold, 1998). Research into children who were native English speakers suggests that they acquire their first word at about one year of age (Barrett, 1986). Then their vocabulary grows at a rapid rate of thousands each year (Miller \& Gildea, 1987; Nagy \& Herman, 1987; Anglin, 1993). At about twenty years of age, the school children have acquired between 50,000 and 250,000 words (Barrett, 1986). However, research investigating the Chinese speaking children's growth rate of Chinese vocabulary is rare. Nevertheless, Chinese children also have remarkable and impressive growth of vocabulary knowledge (Miao \& Zhu, 1992). Paradoxically, on the one hand, vocabulary is acquired rapidly and largely by the school children. On the other hand, the full grasp of vocabulary, such as appropriate choice of vocabulary in expression, variation of vocabulary in expression and the understanding of vocabulary expressing complex and multi-dimensional meanings is manifested through a more protracted development which extends beyond adolescent years.

\subsection{Receptive Vocabulary Knowledge and Productive Vocabulary Knowledge}

Nation $(1990,2001)$ suggested two perspectives of vocabulary knowledge, namely, the receptive knowledge and productive knowledge. Receptive knowledge refers to the recognition and the understanding of the word when it is heard or seen. Productive knowledge refers to the using of the word in spoken and written modes. Productive knowledge, according to Nation $(1990,2001)$, includes and extends receptive knowledge. Research into native English children's early vocabulary development shows that, on average, young children are able to comprehend 50 words before they can produce 10 words (Barrett, 1994). Intrinsically, it is easier to learn vocabulary receptively than productively. Learning a vocabulary productively is found to be more difficult than learning it receptively (Nation, 1990, 2001).

Productive vocabulary as a composite unit involves knowledge of four dimensions, namely, the phonological, orthographical, syntactic and semantic. Phonological knowledge refers to the appropriate pronunciation of a word. Orthographical knowledge refers to the production of the correct written form. Syntactic knowledge refers to the 
production of the word in correct grammatical and collocational patterns. Semantic knowledge refers to the production of the correct meaning a word represents.

\subsection{The Vocabulary of Chinese}

The vocabulary of Chinese, like many languages, can be put into two classes, namely, the content words and the function words (Hu, 1992; Lyons, 1995). Content words which form the major parts of speech in Chinese language, such as nouns, verbs and adjectives, tend to be defined mainly in terms of their semantic contents. Function words which combine the major parts of speech in Chinese language in grammatically well-formed phrases and sentences tend to be defined mainly in terms of their syntactic functions. These two classes of words have respective syntactic and semantic natures. The present study reports the interactions between these two classes of words, and the development of the four linguistic dimensions mentioned in section 1.1, over one year of vocabulary growth in the senior elementary stage of the Cantonese-speaking school children in Hong Kong.

\subsection{The Vocabulary List for Hong Kong Elementary Education (2007)}

In 1996, a Vocabulary List was produced by the Curriculum Development Unit of the Education Department of Hong Kong Special Administrative Region. It was an attempt to compile a prescriptive vocabulary reference for vocabulary learning and vocabulary assessment for elementary education that had yet to be suggested in Hong Kong. The Vocabulary List (HKCDU, 1996) contained 6776 words which were categorized into four sublists. The first two sublists were for the junior elementary, year one to year three (key stage one), whilst the subsequent two sublists were for the senior elementary, year four to year six (key stage two). Tsou, Lee, Tung, Kwan and Au (2000) criticized the Vocabulary List (HKCDU, 1996) for lacking frequently occurring words contained in the newspaper vocabulary. The Vocabulary List (HKCDU, 1996) might integrate with the newspaper words so that the Vocabulary List (HKCDU, 1996) provided to the school children would have words of greater currency. In 2007, the Hong Kong Curriculum Development Unit revised the Vocabulary List (HKCDU, 1996) and further developed it as the Vocabulary List for Hong Kong Elementary Education (Hong Kong Curriculum Development Unit, 2007). Systematic and holistic considerations were given to the construction of the Vocabulary List for Hong Kong Elementary Education (HKCDU, 2007). The 2007 Vocabulary List (HKCDU) contains 9680 textbook and newspaper words, adding more synchronic frequent words as stored in the Mainland China, Taiwan and Hong Kong textbook and newspaper corpuses. The 2007 Vocabulary List (HKCDU) was classified into two key stages, namely, key stage one (i.e. year one to year three) and key stage two (i.e. year four to year six). Thus, the 2007 Vocabulary List (HKCDU) has replaced the former Vocabulary List (HKCDU, 1996) and has offered a prescriptive inventory from which Hong Kong Cantonese-speaking elementary school children may profit at the productive and receptive levels.

\subsection{Previous Studies on Chinese Vocabulary Knowledge}

The overview of the literature on vocabulary studies highlights the attempts on inquiring the vocabulary development in both Cantonese-speaking and Putonghua-speaking children.

In Hong Kong, vocabulary studies on Cantonese-speaking children have been a center of interest since the early 1980s. In the period of the 1980s, there was a strong focus on investigating the lexical competence of the Hong Kong Cantonese-speaking children. The most widely known lexical ability studies in the 1980s are Siu and Lau (1982), Siu (1985), Siu, Fan, Lee and Lai (1987) and Lai (1988). In the 1990s, two significant outputs emerged: the Vocabulary List (HKCDU, 1996) and the Linguistic Variation in Chinese Communities (LIVAC) corpus established by the Language Information Sciences Research Center, City University of Hong Kong, beginning in 1995, with a ten-year time span. These two vocabulary studies deserve much attention as the former provides a prescriptive vocabulary reference for Hong Kong elementary Cantonese-speaking children and the latter offers a descriptive vocabulary database of contemporary Chinese for both linguists and educators. Works from the 2000 onwards have focused on the understanding of the cross-regional learners' vocabulary development (Tsou et al., 2000; Tsou, Kwan \& Liu, 2002). These vocabulary studies indicate a major shift in Hong Kong vocabulary inquiry. Tsou et al. (2000) compared the children's ( $\mathrm{N}=2$ 930) lexical knowledge development in Chinese in four Asian cities, namely, Hong Kong, Shanghai, Singapore and Taipei. The results suggested that Hong Kong and Taipei children showed faster development in their junior secondary school years, followed by slower development in senior secondary school years. Shanghai children already had well-developed lexical skills at an early age, whilst Singaporean children developed their skills steadily across time. Tsou, Kwan and Liu (2002) further suggested that Hong Kong secondary children displayed superior vocabulary knowledge in recognition than in written production. The Hong Kong secondary children showed a breadth of knowledge in both academic and general vocabulary. In addition, the Vocabulary List (HKCDU, 1996) has been revised and further developed as the Vocabulary List for Hong Kong Elementary Education (HKCDU, 2007). 
Since the end of the 1970s, there has been a body of research on vocabulary development of the Putonghua-speaking children in Mainland China. The studies have primarily focused on preschoolers aged at or below six years old. These vocabulary studies have been based mainly on spoken data and have more or less an abundance of findings. Emerging from the vocabulary studies in Mainland China from 1980 onwards are results on various aspects of lexical growth. Firstly, Wu and Zhu(1980) and the Cooperation Study Group of Oral Speech of Preschool Children (1981) have suggested that content words constitute the main part of the Putonghua-speaking children's speech whereas function words account for only about $10 \%$ to $20 \%$ in the Putonghua-speaking children's utterance. In function words, the proportion of interjection seems to decrease gradually when the children grow. Instead, conjunctions, prepositions and adverbs increase slowly but steadily in the children's speech. However, reservations may arise from these studies regarding the sufficient reliability to describe the distributional features in Chinese Putonghua-speaking children's utterance, given that there is a lack of statistics on the ratio of the word class distributed in the adult's speech in China. Next, Zhang (1985) observed the Putonghua-speaking children's acquisition of spatial words. The children's comprehension and production of spatial words make obvious progress from the age of three to four. No marked difference can be found between the children aged five and aged six. Moreover, Zhang (1985) have concluded that the order of lexical acquisition of the spatial words is both determined by the semantic complexity of the spatial words and the children's non-linguistic strategies. Then, Zhu, Cheng and Zhang (1986) found that in the comprehension of personal pronouns, when the Putonghua-speaking children were performing as a third party, they seldom understood that 'he/she (ta)' referred to themselves and they often took 'you(ni)' as themselves. Later, Xu and Min's (1992) study admits that it is not until the age of four that the Putonghua-speaking children can use the three personal pronouns very well. Later, Ying, Chen, Song, Shao and Guo (1993) acknowledged that the preschoolers show difficulty in their use of classifiers. Ying et al. (1993) assert that the acquisition of classifiers primarily depends on rote memorization in addition to the preschoolers' cognitive development, especially when the preschoolers are mature enough in abstract generalization. In the 2000s, Liang, Hao, Wang, Jiang, Yang, Zhang, Zuo, Tarif and Fletcher (2002) studied the vocabulary development of 1056 toddlers from 16-30 months in urban Beijing. They used the Chinese Communicative Development Inventory (Putonghua version) which is a 799 vocabulary checklist included the most common words produced by Putonghua-speaking toddlers. They found that from 16-30 months of age, the development of the Putonghua-speaking children's words was repaid for content words, including both nouns and verbs. By 30 months, the children could produce more that 700 words, including more than 300 nouns and 177 verbs. After 19 months, the Putonghua-speaking children began to use function words. The mean production scores of most kinds of words tended to be higher for females than for males of the same age, with the means for males lagged by one or two months. Later, Chen, Setoh, Meng and Tardif (2009) conducted a case study on a Putonghua-speaking child longitudinally from 6 to 20 months of age. The naturalistic data on caregiver-to-child input were analyzed with the CLAN (Computerized Language Analysis) programme, counting the frequency of nouns, verbs and word position in the caregiver's utterance. Then the development of the child's comprehension and production vocabulary was assessed. Chen et al. (2009) found that the dominance of verbs in Chinese adult's speech influences the children's early vocabulary composition, with a larger cumulative number of verbs than nouns up to 15 months in both comprehension and production. In the same year, Li, Dong, Zhu, Liu and Wu (2009) tested 140 Putonghua-speaking kindergarten children in a battery of morphological awareness tasks in vocabulary acquisition. The results show that morpheme awareness, homograph awareness and radical awareness emerged relatively early in Chinese Putonghua-speaking kindergarteners. Morpheme awareness and homograph awareness played a significant role in the children's vocabulary acquisition in speech whereas homograph awareness and radical awareness were uniquely significant in the children's literacy development. In all, the first hand data and the understanding of various aspects of the Putonghua-speaking children's vocabulary development form a foundation for further research on the Putonghua-speaking children's later vocabulary development.

The above review of the previous attempts to vocabulary studies on both Cantonese-speaking and Putonghua-speaking children suggests that few studies have investigated the acquisition process in relation to the four dimensions of productive knowledge in Chinese vocabulary growth. It is hoped that exploration of the dimensional growth would uncover the relations among the four linguistic dimensions, firstly, to provide clues to the protracted developmental process, and secondly, for developing instructional vocabulary programmes to enhance vocabulary learning.

\subsection{The Purpose of the Study}

The present study investigates longitudinally the productive vocabulary development of the senior elementary Cantonese-speaking children in an Asian city, Hong Kong. Longitudinal investigation presents vocabulary information for the population different from those obtained using cross-sectional studies. Currently, there is a lack of longitudinal information on children's vocabulary development in Hong Kong. Therefore, the present study aims to provide empirical evidence on the longitudinal development occurred in the productive vocabulary knowledge in 
written Chinese among Hong Kong senior elementary Cantonese-speaking children. Secondly, it helps to figure out a prevalent profile of vocabulary growth in relation to the four linguistic dimensions. In these circumstances, the teachers can align their teaching of Chinese vocabulary with the results of the study.

\section{Method}

\subsection{Participants}

The children who formed the population for the study were based in a local elementary school in the mid-levels of Hong Kong. The mid-levels are known as the residential area of the middle class Cantonese speakers in Hong Kong. The elementary school participated in this study, as reported by the school principal, was at the middle range of the academic achievement continuum in the elementary school population in Hong Kong. A class of thirty-eight year four children participated in this longitudinal study. Three children left the school in year five. Therefore useable data for this longitudinal study comprised thirty-five elementary school children. When the children were tested again one year later, their average age was eleven years, one month and one day in year five. The children had normal intelligence, with no language disabilities, as reported by their parents and teachers. According to the information on parents' occupation provided by the parents prior to the beginning of the study, the children came from middle class families. They were native speakers of Cantonese and learned Modern Standard Chinese, the written language, from formal instruction in school. The Hong Kong Education Bureau has divided the schooling from elementary to secondary into four key stages (Learning to Learn - The Way Forward in Curriculum Development, 2001; The New Academic Structure for Senior Secondary Education and Higher Education - Action Plan for Investing in the Future of Hong Kong, 2005), namely, key stage one (junior elementary, year one to year three), key stage two (senior elementary, year four to year six), key stage three (junior secondary, year seven to year nine) and key stage four (senior secondary, year ten to year twelve). Year one to six in Hong Kong elementary education corresponds to year one to six in the west, whilst year seven to twelve in Hong Kong secondary education corresponds to year seven to twelve in the west. The research sample in this study was the elementary children of key stage two (i.e. year four to year six). Thus, for this study, the sample reflects the children population at senior elementary at the middle range of the academic achievement continuum in the Cantonese-speaking community in Hong Kong.

\subsection{Instruments}

The instruments employed in this study were two vocabulary tests which included prescriptive vocabulary items from the textbooks as well as the Vocabulary List for Hong Kong Elementary Education (HKCDU, 2007). Tsou et al. (2000) concludes that prescriptive textbook vocabulary may be more reflective of Hong Kong children' productive vocabulary knowledge whereas descriptive newspaper vocabulary may be more reflective of Hong Kong children' receptive vocabulary knowledge. Hence, the vocabulary items selected in the two vocabulary tests were prescriptive. The selection of the vocabulary items was based on two resources: (a) the 2006 edition of the Xiandai Zhongguo Yuwen (Modern Chinese Language) which was the elementary Chinese language textbook series used in the sample school. (b) the 2007 Vocabulary List (HKCDU). The vocabulary items selected were reviewed by the teachers of the sample school to ensure that the vocabulary items were year appropriate for year four and year five. This process enabled the data gathering to have insight from the practitioners and to be able to separate the pertinent from that which is not. Apart from this, about $60 \%$ of the selected vocabulary items were content words; the rest $40 \%$ were function words. It was necessary that the vocabulary items selected for data gathering should include these two classes of words to unearth the development of the linguistic dimensions in the children' vocabulary growth.

\subsection{Procedures}

The vocabulary tests were used to collect data about the children's ability in and knowledge of the productive vocabulary in written Chinese. In the first vocabulary test, the children were asked to write the words which were read aloud by the researcher. In the second vocabulary test, the children were asked to construct sentences with the words. The four linguistic dimensions, namely, the phonological, orthographical, syntactic and semantic dimensions of the children's productive vocabulary knowledge were analysed in order to discover the development of the gradual mastery of the linguistic dimensions in vocabulary growth. The selection of the senior elementary as the stage to examine was based on the understanding that the senior elementary children have the potential to construct sentences and articulate thoughts better than those at the junior elementary. Since one of the data gathering tasks was sentence constructing test, the senior elementary children have better potential to yield a richness of data pertinent to the task than the junior elementary children in the elementary schooling. The sample children were asked to complete the two vocabulary tests in May 2008 when they were in year four. One year after the normal teaching by their school teacher, the class was tested again on these two vocabulary elicitation tasks in May 2009 at year five.

\subsection{Framework for the Scoring of the Vocabulary Data}

In order to discover the children's productive vocabulary change with respect to the four linguistic dimensions in written Chinese, a framework for the scoring of the vocabulary data was used. 


\subsubsection{Scoring for the phonological dimension}

The phonological knowledge referred to the sound of the vocabulary in Cantonese. The test words were read to the children, who were asked to write each word after they had heard it. The judgment was made on the written renditions of the test words. The homophonic answers as well as the graphic errors ascribed to phonetic confusion were both unacceptable in the test. In this dimension, the scoring key was:

The value of 1: showing correct phonological knowledge of the vocabulary item.

The value of 0 : showing incorrect phonological knowledge of the vocabulary item. Homophone received no credit. A homophone referred to an error which rimed with or had a similar syllable but with different graphic representation and semantic meaning was provided as an answer.

The examples of the scoring of the phonological responses of the vocabulary data are shown in Table 1. (Insert Table 1)

\subsubsection{Scoring for the orthographical dimension}

The orthographical knowledge referred to the unabridged written form of the vocabulary in the Chinese writing system. In this dimension, the scoring key was:

The value of 2: showing correct knowledge of the orthographical form of the vocabulary item.

The value of 1: showing partial knowledge of the orthographical form of the vocabulary item.

The value of 0 : showing misinterpretation of the orthographical form of the vocabulary item. Homophone received no credit.

The examples of the scoring of the orthographical knowledge of the vocabulary are indicated in Table 2. (Insert Table 2)

\subsubsection{Scoring for the syntactic dimension}

The two classes of the vocabulary of modern Chinese, like many languages, are content word and function word. The content word which consists of nouns, verbs, adjectives, numeral / measure words has both lexical and grammatical meanings. The lexical meaning refers to the denotational and non-denotational meanings of the lexemes. The grammatical meaning refers to the meaning of the lexemes which derives from their being members of one category rather than another (Lyons, 1995), for instance, nouns rather than verbs, verbs rather than adjectives, and adjectives rather than numeral / measure words. The function word which consists of adverbs, prepositions, conjunctions, auxiliaries and exclamatory words is defined mainly in terms of their syntactic function. However, certain adverbs may not entirely devoid of meaning. For instance, the adverb “不斷” (on and off) belongs to the function word class. But in the context “街上來往行人不斷” (There is a heavy flow of human traffic in the street.), the Chinese vocabulary “不斷” is a verb in the class of content word (Wang, 1998). The function words have potentiality to combine with one or other of the nouns, verbs, adjectives or with such high-level units as phrases and clauses (Lyons, 1995).

Since the syntactic nature of the two classes of words is distinct, there are dictionaries to describe the respective syntactic features of the members of these two classes of words. Xiandai Hanyu Shici Dapei Cidian (A Dictionary of Notion of Word Collocations of Modern Chinese) (Zhang \& Lin, 1992) has developed the collocation frameworks for nouns, verbs and adjectives for modern Chinese. It has offered the most perceptive insights into the syntactic features of the nouns, verbs and adjectives in modern Chinese that have yet to be suggested. Therefore, the collocation frameworks outlined in the dictionary were used to analyse the syntactic responses of the content words in the vocabulary test of the study. Another dictionary Xiandai Hanyu Xuci Cidian (A Dictionary of Modern Chinese Function Words (Wang, 1998) has adequately described the syntactic features of the adverbs, prepositions. conjunctions, auxiliaries and exclamatory words of modern Chinese. The syntactic features outlined in this dictionary were utilised to analyse the syntactic responses of the function words in the vocabulary test of the study.

In Xiandai Hanyu Shici Dapei Cidian (A Dictionary of Notion of Word Collocations of Modern Chinese) (Zhang \& Lin, 1992), in principle, each definition of meaning of a word is assigned a collocation framework. The matching of a collocation framework with a definition of meaning is described in three levels:

(1) structural constituent level, i.e. collocates may function as [subjects], [predicates], [objects], [complements], [topics], [attributes] or [adverbials];

(2) word class level, i.e. the words to be collocated may be nouns, verbs, adjectives, numbers/measures or modals;

(3) semantic collocation level, i.e. the words to be collocated are classified according to the identicalness or similarity of their meanings which are marked as $a, b, \ldots \ldots$. 
The three levels of the description features the integration of the syntagmatic relations and paradigmatic relations of words.

An example of one of the syntactic collocation outlined in the dictionary for a vocabulary item employed in the study is illustrated as follows:

vocabulary item: 迅速 (promptly)

structural constituent level: the vocabulary item may function as an adverbial

word class level: the word to be collocated can be verbs

semantic collocation level: 發展 ( develop $\sim$ ) 〔 : the vocabulary item〕

Symbolically, the syntactic collocation of the vocabulary item 迅速 "promptly" can be presented as follows: [adverbial] + verb: a,b,.....

Thus, the scoring key for analysing the syntactic responses of the content words in the study was:

The value of 3 for a syntactic response to a content word represented that:

the child showed correct knowledge of the structural constituent level, the word class level and the semantic collocation level of the syntactic collocation of the vocabulary.

The value of 2 for a syntactic response to a content word represented that:

the child was incorrect in any one of the three levels of syntactic collocation of the vocabulary.

The value of 1 for a syntactic response to a content word represented that:

the child was incorrect in any two of the three levels of syntactic collocation of the vocabulary.

The value of 0 for a syntactic response to a content word represented that:

the child was incorrect in the three levels of syntactic collocation of the vocabulary. At the same time, the value of 0 was given to a response when the child did not have knowledge on the meaning of the vocabulary.

The examples of the scoring for the syntactic analysis of the content words in the study are indicated in Table 3 .

vocabulary item: 迅速(promptly)

syntactic collocation: [adverbial] + verb (Insert Table 3)

The syntactic features outlined in Xiandai Hanyu Xuci Cidian (A Dictionary of Modern Chinese Function Words) (Wang, 1998) were used to analyse the syntactic responses of the function words in the study. The syntactic features for the function words can be summarized into three aspects, namely, the structural, the positional and the functional. The structural aspect refers to the correct structure, that is to say, the ways in which the function word connects clauses or sentences in combination. The positional aspect refers to the correct position the function word places in the phrases, clauses or sentences in combination. The functional aspect refers to the logical relation the function word makes between phrases, clauses and sentences in combination. An example of the three aspects of features for a function word employed in the study is indicated as follows:

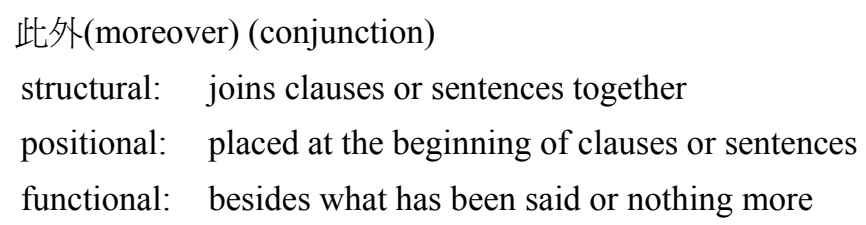

Thus, the scoring key for analysing the syntactic responses of the function words was:

The value of 3 for a syntactic response to a function word represented that:

the child showed correct knowledge of the structural, the positional and the functional aspects of the syntactic collocation of the vocabulary.

The value of 2 for a syntactic response to a function word represented that:

the child was incorrect in any one of the three aspects of the syntactic collocation of the vocabulary.

The value of 1 for a syntactic response to a function word represented that:

the child was incorrect in any two of the three aspects of the syntactic collocation of the vocabulary.

The value of 0 for a syntactic response to a function word represented that: 
the child was incorrect in the three aspects of the syntactic collocation of the vocabulary. At the same time, the value of 0 was given to a response when the child did not have knowledge on the meaning of that function word.

The examples of the scoring for the syntactic analysis of the function words in the study are shown in Table 4 .

vocabulary item: 隨 (along with) (preposition)

The three aspects of the syntactic features for the vocabulary "隨” (along with) are:

structural: with words or phrases, it forms an adverbial modifier in a preposition-structure

positional: the whole preposition-structure can be placed at the beginning of or amid a sentence

functional: used to express the conditions on which something happens. (Insert Table 4)

\subsubsection{Scoring for the semantic dimension}

The semantic analysis of the data is based on the concept of lexical semantics which has been clearly articulated by Lyons (1995) and Geeraerts (1994). Lyons (1995) has outlined the concept of denotational meaning of the lexically full words, that is to say, the lexemes that belong to the major parts of speech, the nouns, verbs and adjectives and some subclasses of adverbs. Geeraerts (1994) has formulated two criteria for the concept of non-denotational meaning to suffice for the description of the meaning of the word.

Firstly, the denotational meaning of a lexeme is invariant and utterance-independent (Lyons, 1995). It is the informative content the lexeme has in the language system, independently of its use on the particular occasions of utterance. Therefore, the denotational meaning of the lexeme does not coincide with 'reference', the extra-linguistic entities, such as situations, relations and processes. For instance, the lexeme 'dog' just denotes a class of entities and the defining properties of the class, without referring to the associations connected with the lexeme. But the denotation of 'dog' is related to other lexemes including 'animal', 'hound', 'terrier', 'spaniel'. Such a relation in the same language system is identified as sense-relations. In short, the denotational meaning of a lexeme does not coincide with 'reference', but corresponds with its linguistic 'sense', the informative content of the lexeme.

Secondly, the denotational meaning of a lexeme coincides with its 'intensions' as opposed to its 'extensions' (Geeraerts, 1994; Lyons, 1995). 'Intension' refers to the lexeme's defining properties, the properties which all members of the class share. 'Extension' refers to a class of entities the lexeme denotes. Intension and extension are complementary aspects of denotational meaning. For instance, the lexeme 'red' denotes not only the class of red things, but also the properties of redness.

Consistent with this orientation, Geeraerts (1994) has outlined two criteria for non-denotational meaning. Firstly, the non-denotational meaning describes the differences in informative content between lexical items that have the same denotational meaning. This leads to the postulation of an emotive type of meaning to explain the distinction between denotationally synonymous items such as 'homosexual' and 'queer'. The word 'homosexual' is more or less a neutral term and the word 'queer' is a negative term. Secondly, the non-denotational meaning of a word describes the informative content of lexical item that lacks denotational meaning. This applies mostly to interjection and interjection-like elements. For instance, 'Hi!' whose value is a greeting expression has no identifiable denotational meaning. An expression of pain such as 'ouch!', or an expression of disgust such as 'ugh!' also presents this type of non-denotational meaning. In fact, Geeraerts' second criterion for non-denotational meaning illustrates the emotive type of lexical meaning as well.

In the light of the above, the meaning of a vocabuary can be analysed as in Table 5. (Insert Table 5)

Therefore, Lyons' (1995) and Geeraerts' (1994) concepts of lexical semantics were utilized to analyse the children's semantic responses to the vocabulary items in the study. For the semantic meaning of the content words, three aspects, the intension, the extension and the emotive meaning were analysed. For the semantic meaning of the function words, the non-denotational meaning was analysed. Examples of the analyses of the semantic meaning of vocabulary items in the study are indicated as follows:

\section{坦誠 candid (adjective)}

intension: simple-hearted and sincere in expression.

extension: conduct, mind, speech, attitude.

emotive meaning: positive

此外 moreover (conjunction)

non-denotational meaning: neutral

即使 even if (conjunction) 
non-denotational meaning: tones expressing "no matter if"

Thus, the scoring key for analysing the semantic responses of the content words was:

The value of 3 for a semantic response to a content word represented that:

the child showed correct knowledge of the denotational and non-denotational meanings of the vocabulary.

The value of 2 for a semantic response to a content word represented that:

the child was incorrect in either any one of the denotational meanings or the non-denotational meaning of the vocabulary.

The value of 1 for a semantic response to a content word represented that:

the child was incorrect in either the denotational meanings or any one of the denotational meanings and the non-denotational meaning of the vocabulary.

The value of 0 for a semantic response to a content word represented that:

the child was incorrect in the denotational and non-denotational meanings of the vocabulary.

At the same time, the value of 0 was given to a response when the child did not have knowledge on the meaning of the vocabulary.

The scoring key for analysing the semantic responses of the function words was:

The value of 1 for a semantic response to a function word represented that:

the child showed correct knowledge of the non-denotational meaning of the vocabulary.

The value of 0 for a semantic response for a function word represented that:

the child was incorrect in the non-denotational meaning of the vocabulary. At the same time,

the value of 0 was given to a response when the child did not have knowledge on the meaning of the vocabulary.

The examples of the scoring for the semantic analysis of the content words in the study are shown in Table 6 .

vocabulary item: 坦誠(candid) (adjective)

intension: simple-hearted and sincere in expression

extension: conduct, mind, speech, attitude

emotive meaning: positive (Insert Table 6)

The examples of the scoring for the semantic analysis of the function words are indicated in Table 7.

vocabulary item 24: 即使(even though)(conjunction)

non-denotational meaning: tones expressing "no matter if" (Insert Table 7)

In summary, the scoring for the vocabulary data in both year four and year five is shown in Table 8. (Insert Table 8)

\subsubsection{Scoring agreement and the inter-rating}

In order to determine the extent to which we can place confidence in the results of the study and the extent to which the literature believes what we have reported, $10 \%$ of the scored vocabulary data in the study were inter-rated. The index of inter-rater agreement was:

(Agree - Disagree)/ (Agree + Disagree) x 100\%. An agreement of 80\% and above was considered acceptable. The result of score agreement in the four dimensions in year four and year five was ranged from $85 \%$ to $100 \%$.

\section{Results}

This section reports the analyses of the data and the results of the study. A doubly multivariate repeated measure design was performed on the longitudinal data to obtain the results of the development of the four linguistic dimensions, namely, the phonological, orthographical, syntactic and semantic dimensions in the vocabulary growth. Principal component analysis (PCA) was conducted to analyse the relations among the phonological, orthographical, syntactic and semantic measures at the two successive time periods, year four and year five. A panel analysis was used to examine the one-year synchronous and test-retest correlations among the four linguistic measures. The longitudinal data were scored in accordance with the scoring scheme explained in section 2.4. The data of the phonological, orthographical and syntactic measures in both year four and year five were scored under each individual condition. 
Moreover, the content and function words within these three measures were scored in the same condition. However, in the semantic measure, the content and function words were assessed with two different scoring scales. For content words, a four-point scale $(3,2,1,0)$ was used while for function words a two-point scale $(1,0)$ was used. Hence, it was necessary to calibrate the raw scores in the four linguistic dimensions in both year four and year five to percentage scores so that comparisons between these linguistic dimensions could be made on the same scale. Accordingly, the statistical analysis was conducted on the percentage scores.

\subsection{The Development of the Four Linguistic Dimensions}

Descriptive statistics including means and standard derivations for the phonological, orthographical, syntactic and semantic measures on the vocabulary items in both year and year five are presented in Table 9. Percentage scores are reported. (Insert Table 9)

A doubly multivariate repeated measures design with one between factor Class- of-Word (Content Word, Function Word) and one within factor Year (Year Four, Year Five) and four measures (Phonological, Orthographical, Syntactic and Semantic) was analysed with the SPSS 17.0 for Windows (2008). The Multivariate Tests showed that the between-subjects factor Class-of-Word was statistically significant $(F(4,30)=5.764, p=0.001$; partial eta squared $=0.44)$, also the within-subjects factor (Year) was statistically significant $(\mathrm{F}(4,30)=19.083, \mathrm{p}=0.000$; partial eta squared $=0.72)$, as was the Year by Class-of-Word interaction $(F(4,30)=4.688, \quad p=0.005$; partial eta squared $=0.39$ ). Close examination for the univariate tests for the between-subjects (Class-of-Word) effect showed that only the syntactic measure was statistically significant $(\mathrm{F}(1,33)=10.092, \mathrm{p}=0.03$; partial eta squared $=0.234)$. The univariate test results also showed that for the within-subjects (Year 4, Year 5) effects, all measures but the semantic measure for the Year by Class-of-Word interaction were statistically significant. The results are shown in Table 10. (Insert Table 10)

Because there was a significant Year by Class-of-Word interaction, the interactions for all measures were examined first before trying to interpret the Year main effects. The Year by Class-of-Word interactions are displayed in Figure 1. (Insert Figure 1)

\subsubsection{Phonological measure}

The significant interaction effect for the phonological measure was due to the large mean difference between content $(\underline{M}=73.571)$ and function $(\underline{M}=61.714)$ words at year four, while at year five the mean for content and function words showed very little difference (content word: $\underline{\mathrm{M}}=82.429$; function word: $\underline{\mathrm{M}}=82.667$ ). However, the interval for the phonological measure also showed that there was a strong main effect for year. Both the function and content words were marked by large increases from year four to year five. For function words, the mean increase was from 61.714 (year four) to 82.667 (year five), while for contents words, it was from 73.571 (year four) to 82.429 (year five). Thus in contrast with the content words, the function words looked more difficult at year four but increased strikingly at year five.

\subsubsection{Orthographical measure}

The significant interaction effect for the orthographical measure was due to the large mean difference between content $(\underline{M}=76.143)$ and function $(\underline{M}=63.238)$ words at year four, while at year five the mean for content and function words showed little difference (content word: $\underline{\mathrm{M}}=84.643$; function word: $\underline{\mathrm{M}}=85.429$ ). However, the interval for the orthographical measure showed that there was also a strong main effect for year. Function words increased from 63.238 (year four) to 85.429 (year five) and content words increased from 76.143 (year four) to 84.643 (year five). In contrast with the content words, the function words also looked difficult at year four but increased strikingly at year five for the orthographical measure.

\subsubsection{Syntactic measure}

The significant interaction effect for the syntactic measure was due to the large mean difference between content and function words at year four and at year five, too. However, the mean difference between content word and function word was somewhat larger in year four (content word: $\underline{M}=69.095$; function word: $\underline{M}=44.635$ ) than at year five (content word: $\underline{\mathrm{M}}=84.095$; function word: $\underline{\mathrm{M}}=74.603$ ). The interval for the syntactic measure also showed that there was a strong main effect for year, which once more was more pronounced for function words (from 44.635 (year four) to 74.603 (year five)) than content words (from 69.095 (year four) to 84.095 (year five)). The between-subjects effects showed that for the syntactic measure, the mean (76.595) of the content words was significantly higher than the mean (59.619) of the function words. The effect size for the mean difference as measured by partial eta squared was 0.234 . Thus about $23 \%$ of the variance in the syntactic measure could be explained by the Class-of-Word factor. Hence, there is significant difference between content words and function words for the mean score of the syntactic measure. In contrast with the content words, the function words looked difficult at year four and remained difficult at year five for the syntactic measure. 


\subsubsection{Semantic measure}

There was no significant interaction effect for the semantic measure because of the small mean difference between content $(\underline{\mathrm{M}}=48.810)$ and function $(\underline{\mathrm{M}}=44.190)$ words at year four and the even smaller difference at year five (content word: $\underline{M}=68.524$; function word: $\underline{M}=67.810$ ). However, there were similar strong main effects for both content (from 48.810 (year four) to 68.524 (year five)) and function words (44.190 (year four) to 67.810 (year five)). Compared with the content words, the function words appeared slightly more difficult at year four and the difference between content and function words were almost non-existent at year five.

\subsection{The Relations of the Four Linguistic Dimensions in Vocabulary Growth}

Zero-order correlations between the phonological, orthographical, syntactic and semantic measures for the vocabulary items in both year four and year five are presented in Table 11. (Insert Table 11)

Inspection of the zero-order correlations in Table 11 shows two well defined clusters, one between the phonological and orthographical measures and the other one between the syntactic and semantic measures. Correlations between the phonological and orthographical measures ranged from .462 between the phonological measure at year four and the orthographical measure at year five to .991 between the phonological and the orthographical measures at year four. The minimum correlation for the syntactic and semantic cluster was .437 between the syntactic measure at year four and the semantic measure at year five, while the maximum correlation was .763 between the syntactic and semantic measures at year five. All the correlations within these two clusters were statistically significant at the .01 level. The between cluster correlations ranged in magnitude from .022 to .428 , and only the correlations between the syntactic and phonological measures at year four $(\mathrm{r}=.405)$ and the syntactic and orthographical measures at year four $(\mathrm{r}=.428)$ were statistically significant $(\mathrm{p}<.05)$. However, inspection of the scatter plots for these two pairs of variables showed that the significant correlations resulted from the presence of a few outlying observations.

Principal component analysis (PCA) of the zero-order correlations in Table 11 confirmed the presence of the two distinct clusters of variables described above. The PCA results showed that two components explained $75.624 \%$ of total variance. An oblique rotation of these two components showed two well defined clusters of variables for which the two components were only weakly correlated $(\mathrm{r}=.122)$, suggesting that we are dealing with two relatively independent clusters of variables. The pattern and structure matrices for the promax rotated solution are shown in Table 12 below. (Insert Table 12)

From the pattern and structure matrices we see that the phonological year four, phonological year five, orthographical year four, orthographical year five measures mainly define the first component. The loadings of these four measures on component one are all greater than 0.8 . On the other hand, the syntactic year four, syntactic year five, semantic year four, semantic year five measures mainly define the second component. Likewise, the loadings of these four measures on component two are all greater than 0.8 . The similarity between the structure matrix results with those of the pattern matrix is because of the small correlation between these two components. Thus, the two components from the principal component analysis associate phonology and orthography measures on the one hand, and syntax and semantics measures on the other hand.

\subsection{The One-year Panel Correlations of the Four Linguistic Measures}

As noted, two linguistic components were found to be important in vocabulary development. The first component was associated with the phonology and orthography measures while the second component was associated with the syntax and semantics measures. Since all four linguistic measures were measured at years four and five, it was possible to examine the synchronous correlations (Rosenthal \& Rosnow, 1991) between the linguistic measures defining each component and the test-retest correlations for these linguistic measures. If we let $\mathrm{A}$ and $\mathrm{B}$ represent two measures, each of which is measured individually at two successive time points (time one: A1, B1; time two: A2, B2), then synchronous correlations at time one and time two can be represented by $r_{A 1, B 1}$ and $r_{A 2, B 2}$, respectively, while the test-retest correlations can be represented by $r_{A 1, A 2}$ and $r_{B 1, B 2}$, respectively. Synchronous correlations $\left(r_{A 1, B 1}\right.$ and $r_{A 2, B 2}$ ), when compared with one another, indicate the stability of the relationship between measures $\mathrm{A}$ and $\mathrm{B}$ over time, while test-retest correlations $\left(r_{A 1, A 2}\right.$ and $\left.r_{B 1, B 2}\right)$ indicate the stability of each measure (A and $\left.\mathrm{B}\right)$ over time.

\subsubsection{Phonological-Orthographical correlational results}

Figure 2 presents the synchronous and test-retest correlations for the phonological-orthographical component. (Insert Figure 2)

The synchronous correlations between the phonological measure and the orthographical measure at year four (.991) $\left(r_{A 1, B 1}\right)$ and at year five (.955) $\left(r_{A 2, B 2}\right)$ were large and very similar, differing by only a small amount (.036), suggesting that the relationship between these two measures appears stable, that is, stationary (Rosnethal \& Rosnow, 1991) from year four to year five. In other words, the high synchronous correlations between the phonological and the 
orthographical measures at both years four and five suggest a strong relationship in productive vocabulary and that this relationship in vocabulary development is stationary over time. The test-retest correlations for the phonological (.537) $\left(r_{A 1, A 2}\right)$ and orthographical (.470) $\left(r_{B 1, B 2}\right)$ measures were of similar magnitude, while the test-retest correlations were of moderate size indicating that the rank ordering of the items on both these measures changed somewhat over this one-year time period. Nevertheless, the test-retest correlations of this magnitude are consistent with the literature (Weizman \& Snow, 2001).

\subsubsection{Syntactic-Semantic correlational results}

The synchronous and test-retest correlations for the syntactic-semantic component are shown in Figure 3. (Insert Figure 3)

The synchronous correlations between syntactic and semantic measures at years four (.753) $\left(r_{A 1, B 1}\right)$ and five (.763) $\left(r_{A 1, B 1}\right)$ were almost identical, suggesting that the relationship between these two measures is stationary over time. In other words, the synchronous relationship between syntactic and semantic measures is relatively stable from year four to year five. That is to say, the moderately high synchronous correlations between the syntactic and semantic measures at both years four and five indicate a relatively strong relationship in productive vocabulary and that this relationship in vocabulary development is stationary over time. The test-retest correlation for the syntactic measure $(.706)\left(r_{A 1, A 2}\right)$ was a little larger than that for the semantic measure (.597) $\left(r_{B 1, B 2}\right)$, indicating that the syntactic measure is slightly more stable over time than the semantic measure. That is, the change in the rank ordering of the items over a one year period for the syntactic measure was somewhat more stable than for the semantic measure in vocabulary acquisition. Nonetheless, the magnitude of these one-year test-retest correlations shows both measures to be fairly stable aspects of vocabulary acquisition.

In summary, the synchronous and test-retest correlations for both the phonological-orthographical and syntactic-semantic components were found to be stable over a one-year time period. In other words, these two distinct aspects of vocabulary knowledge are stable characteristics in the productive vocabulary.

\subsection{General Language Competence across Phonology, Orthography and Syntax}

In addition to the two linguistic components, namely, the phonological and orthographical component, the syntactic and semantic component unravelled in the relations of the four linguistic measures in the vocabulary development, two pairs of correlated variables were found. They were the syntactic and phonological measures at year four $(\mathrm{r}=.405)$ and the syntactic and orthographical measures at year four $(\mathrm{r}=.428)$. The correlations of these two pairs of variables were statistically significant at the .05 level. These two pairs of variables in their respective scatter plots show the presence of five identical vocabulary outliers which contributed to the significant correlations. If these five identical outliers were removed, the correlations of these two pairs of variables would have been insignificant. In order to explain the occurrence of the five outliers, a qualitative analysis of these five vocabulary items was conducted, focusing on their phonological, orthographical and syntactic production at year four. It is noted from the data that the children who had correct production on the phonological side could attain similar results on the syntactic and orthographical sides simultaneously. Hence, given some general language competence across the phonological, orthographical and syntactic dimensions by some children, the association across the phonological, orthographical and syntactic dimensions was formed. However, the strength of this association is indistinct on the account of the weak correlations among these three dimensions.

\section{Discussion}

Based on the above-mentioned significant findings occurred at the senior elementary schooling of the Hong Kong Cantonese-speaking children, a profile of productive vocabulary growth in relation to the written Chinese is proposed.

\subsection{The Difference between the Content and the Function Words in Vocabulary Acquisition}

The significant main year effect for all the four linguistic dimensions, namely, the phonological, orthographical, syntactic and semantic dimensions, indicates that the children had significant production improvement in all the four linguistic dimensions of the vocabulary items from year four to year five. However, the dimensional change between the content and the function words is different in the vocabulary growth. The production of the function words was consistently lower than that of the content words in the four linguistic dimensions in year four. In year five, the phonological, orthographical and semantic production of the function words got closer to the content words. Nevertheless, the syntactic production of the function words was still considerably below the content words in year five. This indicates that the syntactic production of the function words is weaker than that of the content words for the children in both year four and year five. The result of the univariate tests for the between-subjects (class-of-word) effect which showed that only the syntactic measure had significant difference between the content and the function 
words for the mean scores (see section 3.1) is supportive of the weak syntactic acquisition of the function words. Hence, we may say that a weaker function word acquisition occurs at this learning stage. The acquisition of function words appears to be a protracted process when compared with the acquisition of content words in vocabulary growth.

\subsection{The Associations among Linguistic Dimensions in Vocabulary Development}

Two components associated phonology and orthography measures on the one hand, and syntax and semantics measures on the other hand were found in the vocabulary development. In addition, for the phonological-orthographical component, the strong relationship between phonology and orthography were stable from year four to year five. Likewise, for the syntactic-semantic component, the relatively strong relationship between syntax and semantics were stable from year four to year five. Given these encouraging results, the association among the four linguistic dimensions in the vocabulary development in written Chinese at the senior elementary of the Cantonese-speaking children is formed.

The phonological side of the component refers to the sound of the vocabulary in Cantonese. The orthographical side of the component is regarded as the unabridged standard form of the vocabulary in the Chinese writing system. In human language, the writing system represents utterances of that particular spoken variety (Sampson, 1985). Most of the time, Chinese vocabulary consists of more than one morpheme. For instance, the Chinese vocabulary “牙醫” (dentist) is made up of two free morphemes "tooth-doctor". In principle, there is one symbol in the Chinese scripts for one morpheme. Such a symbol is called Chinese character. Individual Chinese character is always pronounced in Cantonese in the Hong Kong Community. For instance, the two Chinese characters “牙” (tooth) and “醫” (doctor) are linked to the spoken Cantonese canonical form [ngaa4] and [ji1] respectively. Whenever the Cantonese-speaking children learn the writing form of the Chinese vocabulary, they simultaneously learn the standard Cantonese pronunciation. The strong association between phonology and orthography suggests that a strong link between the phonological ability and the orthographical ability occurs in the children's productive vocabulary development.

Apart from the phonological-orthographical component, this study also reveals a relation between the syntactic dimension and the semantic dimension during the vocabulary growth. The association between syntax and semantics is relatively strong in vocabulary acquisition. First and foremost, for the content words, the syntactic side refers to the permissible combination of the lexical item with another word in written Chinese. Three levels, namely, the constituent level, the word class level and the semantic collocation level were taken into account of the permissible syntactic combination. On the other hand, the semantic side is regarded as the composition of the denotational meaning and non-denotational meaning of a word. Clearly, the syntactic side and the semantic side are basically in themselves independent and distinct. Nevertheless, these two sides are co-existing and interrelated dimensions which show the production of the children's vocabulary knowledge. The syntactic combination offers a permissible structure and the semantic meaning of the lexical item is realized in the permissible syntactic structure. This relationship is significant in vocabulary production. For instance, the semantic meaning of the vocabulary 炎熱 (torrid) includes the following three aspects:

$$
\begin{aligned}
& \text { intension: intensively hot } \\
& \text { extension: weather / season } \\
& \text { emotive meaning: negative }
\end{aligned}
$$

On the other hand, one of the permissible syntactic combinations for the vocabulary 炎熱 (torrid) is “[attribute] + noun.” In the children's production “炎熱的夏天，使我流了一身大汗。” (I sweat profusely in the torrid summer.), the syntactic combination of the vocabulary is correct. The vocabulary “炎熱” (torrid) was used as an attribute and was used to combine with a noun. The knowledge of the syntagmatic relation was well shown in the syntactic structure because the collocated noun referred to a season with hot weather, the "summer". At the same time, the noun “ummer"served as a compatible class of entity which the vocabulary “炎熱”(torrid) denoted. Besides, the properties of the vocabulary 熱” (torrid) was further and adequately expressed in the clause “我流了一身大汗” (I sweat profusely). The said clause exhibited simultaneously a sense of unpleasantness for the vocabulary. This example demonstrates the compatibility of the syntactic and the semantic sides of a vocabulary item in the children' production. However, the compatible link between the syntactic and the semantic dimensions depends, to the greatest extent, on the children' ability. In this regard, the association between syntax and semantics in the vocabulary development from the study may suggest a relatively strong link between the syntactic ability and the semantic ability in the content words in vocabulary growth at this learning stage.

Apart from the result in the content words, this study also has the same result in the function words. The phenomenon of association between syntax and semantics is the same for the class of function words as for the content words. The syntactic side for the function words refers to the admissible construction of the lexicon with another word or phrase 
into well-formed structure in written Chinese. Three aspects, to wit, the structural, the positional and the functional aspects were considered in the admissible construction. The semantic side for the function words is regarded as the non-denotational meaning of the word. It is reasonable to say that the semantic side of the function words may not have any lexical meaning at all. The semantic side, that is, the non-denotational meaning is dependent upon the meaning of the phrase or the sentence in which the syntactic side of the vocabulary occurs. Therefore, the compatible relationship between the syntactic side and the semantic side is significant in vocabulary production as well. For instance, the syntactic structure of the vocabulary “此外” (moreover) includes the following three aspects:

structural: joining clauses or sentences together

positional: placed at the beginning of clauses or sentences

functional: besides what has been said or nothing more

The non-denotational meaning of the vocabulary is neutral. In the children's production “讀課外書, 可以增加知 識。此外, 還可以提高寫作能力。”Reading more books can increase our knowledge. Moreover, it can enhance our writing skills.), the vocabulary “此外” (moreover) joined the two sentences “讀課外書, 可以增加知識” (Reading more books can increase our knowledge.) and “可以提高寫作能力” it can enhance our writing skills). It was placed at the beginning of the next sentence, introducing another new point of view to support the previous statement. At the same time, no distinct tone was attached to the introduction. The syntactic-semantic relation is compatible in the production of this vocabulary item. Similarly, the compatible link between the syntactic and the semantic dimensions depends, to the greatest extent, on the children' ability. In these circumstances, the association between syntax and semantic dimensions in the vocabulary development from the study may also suggest a rather strong link between the syntactic ability and the semantic ability in the function words in vocabulary production at this learning stage.

The pedagogical implications from the study are two-faceted. Firstly, the aspects of vocabulary knowledge that emerged from the present study correspond to the senior elementary of the Hong Kong Cantonese-speaking children. Hence, we can say that they are important characteristics for measuring the senior elementary children's production vocabulary knowledge. This is notably useful for the teachers to follow the progress of individual development in vocabulary learning. In addition, it would enable the children themselves to reflect upon their own vocabulary development apart from the achievements of others as well as to make efforts to develop themselves according to the stage they are in. Secondly, the current approach in vocabulary teaching for the senior elementary Cantonese-speaking children in Hong Kong is explicit instruction. The teachers usually teach the children the pronunciation of the words, drill the children in the written form of the words, teach the word meanings directly to the children and instruct the children to construct sentences with the words verbally and in writing. Outside the explicit vocabulary instruction, the teachers promote regular reading to increase the children's vocabulary knowledge. A large amount of time appears to have been devoted to the teaching of word 'comprehension'. It is not to say that such instruction may not still be valuable. However, it is necessary to elevate the receptive knowledge to its productive level, since fundamentally, an efficient and accurate production of vocabulary in written Chinese constitutes a major pre-requisite for Chinese language competence. In view of the present findings, the function words appear to be relatively protracted in acquisition. This may suggest that the senior elementary Cantonese-speaking children need to spend relatively more time on learning the function words than on the content words. It would be profitable for the children to receive an amount of instruction on better word production, with an emphasis on the function word production. The analysis of the four aspects, namely, the structural, positional, functional and non-denotational of the function words are necessary and useful. The potentially of such analysis in contributing to productive vocabulary development is evident from a view of the results of the present research.

\section{Conclusion}

This longitudinal study provides a vocabulary acquisition profile in the written Chinese of the Cantonese-speaking children at senior elementary in Hong Kong. The examination reveals the underlying process which indicates the gradual mastery of the linguistic dimensions as well as the two classes of words of the vocabulary knowledge. The vocabulary development in written Chinese at this learning stage is characterized in the following aspects: there is dimensional difference between the content and the function words in vocabulary growth, in which the syntactic acquisition of the function words seems to take a longer time. Further, two relatively independent aspects of vocabulary knowledge, namely, the phonological-orthographical and the syntactic-semantic emerge.

\section{References}

Anglin, J. M. (1993). Vocabulary development: A morphological analysis. Monographs of the Society for Research in Child Development, 58(10), Serial no. 238, (Chapter 2).

Barrett, M. D. (1986). Early semantic representations and early word usage. In S. A. Kuczaj, \& M. D. Barrett (Eds). The development of word meaning (pp. 39-67). New York: Springer-Verlag. 
Barrett, M. D. (1994). Language acquisition: vocabulary. In R. E. Asher (Ed.). The encyclopedia of language and linguistics (Vol. 4), (pp. 1927-1931). Oxford, New York: Pergamon Press.

Chen, J., Setoh, P. P., Meng, X. Z., \& Tarif, T. (2009).The influence of adult input on children's early word learning: a case study of a Mandarin-speaking child. Acta Psychologica Sinica. 41(8), 715-725. http://dx.doi.org/10.3724/SP.J.1041.2009.00715

Education and Manpower Bureau. (2005). The new academic structure for senior secondary education and higher education - action plan for investing in the future of Hong Kong. Hong Kong: Hong Kong Government, (Chapter 3).

Geeraerts, D. (1994). Lexical meaning: types. In R. E. Asher (Ed.). The encyclopedia of language and linguistics (Vol.4), (pp. 2153-2155). Oxford, New York: Pergamon Press.

Hong Kong Curriculum Development Unit. (1996). Vocabulary list. Hong Kong: Education Department.

Hong Kong Curriculum Development Council. (2001). Learning to learn - the way forward in curriculum development. Hong Kong: Education Department, (Chapter 2).

Hong Kong Curriculum Development Unit. (2007). Vocabulary lists for Hong Kong elementary education. Hong Kong: Education and Manpower Bureau, (Chapters 2 and 3).

Hu, Y. S. (1992). Xiandai Hanyu (Zengdingben). (Modern Chinese). Hong Kong: Joint Publishing (H.K.) Co. Ltd, (Chapter 4).

Lai, T. C. (1988). Statistical analysis of word choice in Chinese writing in secondary school students of different abilities. M.A. thesis, Chinese University of Hong Kong.

Lenneberg, E. H. (1967). Biological foundations of language. New York: John Wiley, (Chapter 4).

Liang, W. L., Hao, B., Tarif, T., Fletcher, P., Wang, S., Jiang, Y. Q., Yang, Y. L., \& Zhang, Z. X. (2002). Vocabulary development of toddlers in urban Beijing. Chinese Journal of Pediatrics. 40(11), 650-653

Li, L., Dong, Q., Zhu, J., Liu, J. P., \& Wu, X. C. (2009). The role of morphological awareness in kindergarteners' linguistic skill development. Psychological Science. 32(6), 1291-1294

Lyons, J. (1995). Linguistic semantics. London: Cambridge University Press, (Chapter 2).

Miao, X. C., \& Zhu, M. S. (1992). Language development in Chinese children. In H. C. Chen, \& O. J. L. Tseng (Eds.). Language processing in Chinese (pp. 237-276). Edsevier Science Publishers B.V.

Miller, G. A., \& Gildea, P. M. (1987). How children learn words. Scientific American. 257, 94-99. http://dx.doi.org/10.1038/scientificamerican0987-94

Nagy, W. E., \& Herman, P. A. (1987). Breadth and depth of vocabulary knowledge: Implications for acquisition and instruction. In M. G. McKeown \& M. E. Curtis (Eds.). The nature of vocabulary acquisition (pp. 19-35): Hillsdale, NJ: Erlbaum.

Nation, I. S. P. (1990). Teaching and learning vocabulary. Boston, MA: Heinle \& Heinle, (Chapter 3).

Nation, I. S. P. (2001). Learning vocabulary in another language. Cambridge: Cambridge University Press, (Chapter 2).

Nippold, M. A. (Ed.). (1988). Later language development: Ages nine through nineteen. Boston: College-Hill, (Chapter 1).

Rosenthal, R., \& Rosnow, R. L. (1991). Essentials of behavioral research: methods and data analysis. McGraw-Hill, Inc, (Chapter 14).

Sampson, G. (1985). Writing systems: a linguistic introduction. London:Hutchinson, (Chapter 8 ).

Siu, P. K. (1985). An analysis of knowledge of Chinese characters and words (Zhongwen Zi Ci Renshi Nengli Zhi Fenxi). Chinese University of Hong Kong Education Journal. 13(2), 16-20

Siu, P. K., Fan, K., Lee, L. M., \& Lai, T. C. (1987). A study of the Chinese vocabulary of junior secondary students in Hong Kong (Xianggang Chuzhong Xuesheng Zhongwen Cihui Yanjiu). Hong Kong: Education Department (Chapters $1-7)$.

Siu, P. K., \& Lau, S. (1982). The free association patterns of Hing Kong kindergarten pupils for Chinese characters (Xianggang Youziyuan Xuesheng de Hanzi Lianxiang Moshi). In H. Kao and C.M. Cheng (Eds.). Studies on the psychology of the Chinese language (Zhongguo Yuwen de Xinlixue Yanjin)(pp. 103-121). Taipei: Crane.

SPSS, Inc. (2008). SPSS for Windows, release 17. Chicago, IL: SPSS, Inc.

The Cooperation Study Group of Oral Speech of Preschool Children (1981). Investigation into the development of the oral speech of preschool children. Information on Psychological Sciences. 5, 30-37 
Tsou, B. K. Y., Kwan, A. S. F., \& Liu, G. K. F. (2002). The developing lexicon: the case of Hong Kong Secondary Students. In H. S. R. Kao, C. K. Leong, \& D. G. Gao (Eds). Cognitive neuroscience studies of the Chinese language (pp. 285-305).Hong Kong: Hong Kong University Press.

Wang, Z. Q. (1998). Xiandai Hanyu Xuci Cidian (A dictionary of modern Chinese function words). Shanghai: Shanghai Cishu Chubanshe.

Weizman, Z. O., \& Snow, C. E. (2001). Lexical input as related to children's vocabulary acquisition: Effects of sophisticated exposure and support for meaning. Developmental Psychology. 37(2), 265-279. http://dx.doi.org/10.1037/0012-1649.37.2.265

Wu, H. Y., \& Zhu, J. Q. (1980). An investigation of 2 to 6-year old children's language development. Child Psychology and Educational Psychology. 3-4, 19-25

Xu, Z. Y., \& Min, R. F. (1992). A study on the acquisition of personal pronouns by Chinese-speaking children. Acta Psychologica Sinica. 24(4), 337-345

Ying, H. C., Chen, G. P., Song, Z. G., Shao, W. M., \& Guo, Y. (1993). Characteristics of 4 to 7-year-old children in mastering quantitatives. Information on Psychological Sciences. 6, 24-32

Zhang, R. J. (1985). On children's mastery of expressions denoting space. Journal of East China Normal University (Educational Science Edition). 4, 35-46

Zhang, S. K. \& Lin, X. G. (Eds.). (1992). Xiandai Hanyu Shici Dapei Cidian (A dictionary of notion of word collocations of modern Chinese). Beijing: Commercial Press.

Zhu, M. S., Cheng, G. P., \& Zhang, R. J. (1986). Young children's comprehension of personal pronouns. Acta Psychologica Sinica. 18, (4), 356-364

Table 1.

\begin{tabular}{ccc}
\hline \multicolumn{2}{c}{ Vocabulary item (Phonological Responses) } & Scoring \\
\hline 一番 “again and again” & [jat1 faan1] & 1 \\
一翻 (homophone error) & [jat1 faan1] & 0 \\
一般 & [jat1 bun1] & 0 \\
\hline
\end{tabular}

Examples of the Scoring in the Phonological Dimension

Table 2.

\begin{tabular}{ccc}
\hline Vocabulary items (Orthographical responses) & Scoring \\
\hline 誠懇 “cordial” & {$\left[\begin{array}{ll}\text { sing4 } & \text { han2}\end{array}\right]$} & 2 \\
誠恨 (homophone error) & {$\left[\begin{array}{ll}\text { sing4 } & \text { han6 }\end{array}\right]$} & 0 \\
$*$ & & \\
品德 “morality” & {$\left[\begin{array}{ll}\text { ban2 } & \text { dak1 }\end{array}\right]$} & 0 \\
品 & {$\left[\begin{array}{ll}\text { ban2 } & ]\end{array}\right.$} \\
$*$ & & 1 \\
\hline
\end{tabular}

* no knowledge of the orthographical form

Examples of the Scoring in the Orthographical Dimension 
Table 3.

\begin{tabular}{|l|c|}
\hline $\begin{array}{l}\text { Child's response: } \\
\text { 意外發生時, 我們應該迅速地報警。 }\end{array}$ & $\begin{array}{c}\text { Score } \\
3\end{array}$ \\
\hline $\begin{array}{l}\text { Translation: } \\
\text { We should call the police promptly when an accident occurs. }\end{array}$ & $\begin{array}{l}1 \text { structural } \\
\text { constituent level }\end{array}$ \\
\hline $\begin{array}{l}\text { Analysis: } \\
\text { The child exhibited his knowledge of the syntactic collocation of the vocabulary. } \\
\text { The vocabulary was used correlatively with the auxiliary word “地” to successfully } \\
\text { form an adverbial. The verb “報警” (a verb phrase “call the police” in English) was } \\
\text { used to combine with the said adverbial and formed a grammatical well-formed } \\
\text { phrase. The meaning of the said verb “報警” fully demonstrated the true meaning in } \\
\text { this grammatical unit. Therefore, a score of three was given to the response. }\end{array}$ & $\begin{array}{l}\text { w comantic } \\
\text { collocation level }\end{array}$ \\
\hline
\end{tabular}

\begin{tabular}{|l|c|}
\hline $\begin{array}{l}\text { Child's response: } \\
\text { 火箭起飛後，便要迅速地 “飛過大氣層。 }\end{array}$ & $\begin{array}{c}\text { Score } \\
2\end{array}$ \\
\hline $\begin{array}{l}\text { Translation: } \\
\text { After the launch of the rocket, it promptly *flew past the atmosphere layer. }\end{array}$ & $\begin{array}{l}1 \text { structural } \\
\text { constituent level }\end{array}$ \\
\hline $\begin{array}{l}\text { Analysis: } \\
\text { The vocabulary “迅速” was used correlatively with the auxiliary word “地” to } \\
\text { successfully form an adverbial. The verb phrase “飛過大氣層” (flew past the } \\
\text { atmosphere layer) was used to combine with the said adverbial and formed a } \\
\text { grammatical well-formed unit. However, the meaning of the said verb phrase was } \\
\text { inadequately expressed for the true meaning of "flying beyond". Therefore, a score } \\
\text { of two was given to this response. }\end{array}$ & $\begin{array}{l}\text { lemantic } \\
\text { collocation level }\end{array}$ \\
\hline
\end{tabular}

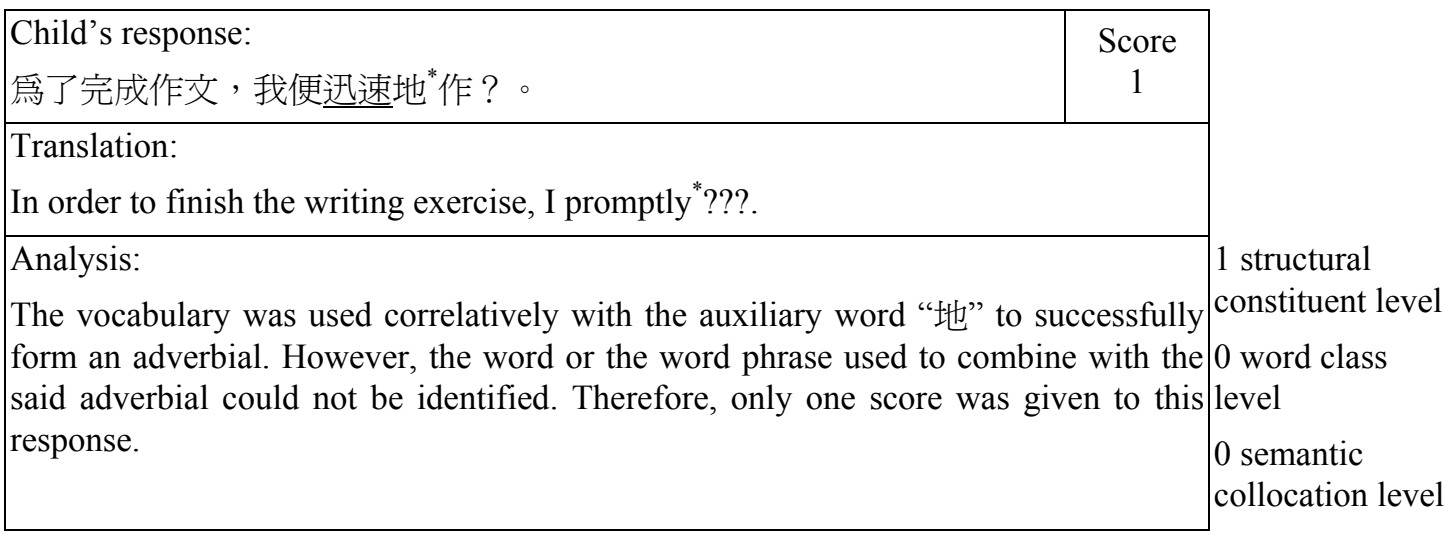

\begin{tabular}{|l|c|}
\hline $\begin{array}{l}\text { Child's response: } \\
\text { 在跑步比賽中, 我已迅速的速度跑到終點。 }\end{array}$ & $\begin{array}{c}\text { Score } \\
0\end{array}$ \\
\hline $\begin{array}{l}\text { Translation: } \\
\text { He reached the finishing point at *prompt speed in the running contest. }\end{array}$ & $\begin{array}{l}\text { * structural } \\
\text { Analysis: } \\
\text { The vocabulary was used mistakenly to correlate with the auxiliary word “的” and } \\
\text { therefore unsuccessfully formed an adverbial. The noun “速度” (speed) was used to } \\
\text { combine with the word and therefore formed a grammatical ill-formed combination. } \\
\text { The meaning of the said noun also did not semantically collocate with the word. } \\
\text { Therefore, a score of } 0 \text { was given to this response. }\end{array}$ \\
$\begin{array}{l}\text { level } \\
0 \text { semantic } \\
\text { collocation level }\end{array}$ \\
\hline
\end{tabular}


Table 4.

\begin{tabular}{|c|c|}
\hline $\begin{array}{l}\text { Child's response: } \\
\text { 隨 大雨的來臨, 我們的戶外活動要取消了。 }\end{array}$ & \\
\hline $\begin{array}{l}\text { Translation: } \\
\text { Our outdoor activities have to be cancelled following the heavy rain. }\end{array}$ & \\
\hline $\begin{array}{l}\text { Analysis: } \\
\text { The child exhibited his knowledge of the syntactic collocation of the vocabulary. The vocabulary was } \\
\text { used to combine with the noun phrase "大雨的來臨" (the coming of the heavy rain) to successfully form } \\
\text { a preposition-structure. The said preposition-structure added information about the predicate in the } \\
\text { sentence. Moreover, the whole preposition-structure was placed at the beginning of the sentence to } \\
\text { express circumstances which directly affected the incident in the sentence. Therefore, a score of three was } \\
\text { given to this response. }\end{array}$ & $\begin{array}{l}1 \text { structural } \\
1 \text { positional } \\
1 \text { functional }\end{array}$ \\
\hline
\end{tabular}

\begin{tabular}{|l|c|}
\hline Child's response: & Score \\
隨 時代的改變, 我們的服裝也變得很流行了。 & 2 \\
\hline
\end{tabular}

Translation:

Following the passage of time, our costume ${ }^{*}$ has became very popular.

Analysis:

The vocabulary was used to combine with the noun phrase “時代的改變” (the passage of time) to successfully form a preposition-structure. The said preposition-structure also added information about the predicate in the sentence. The whole preposition-structure was placed at the beginning of the sentence to 1 positional express circumstances. However, the happening in the sentence was not directly derived from this 0 functional condition. The child's response should be “隨 時代的改變，我們的服裝也改變了不少。” (Following the passage of time, our costume has changed a lot.) Therefore, a score of two was given to this response.

\begin{tabular}{|c|c|}
\hline $\begin{array}{l}\text { Child's response: } \\
\text { 香港隨＂經濟一直改變。 }\end{array}$ & \\
\hline $\begin{array}{l}\text { Translation: } \\
\text { Hong Kong is changing along with the * economy. }\end{array}$ & \\
\hline $\begin{array}{l}\text { Analysis: } \\
\text { The vocabulary was used to combine with the noun “經濟” (economy) to form a preposition-structure. } \\
\text { However, the said preposition-structure was unsuccessful in adding information about the predicate in the } \\
\text { sentence. Moreover, the said preposition-structure failed to express circumstances which directly affected } \\
\text { the happenings in the predicate. The child's response should be “香港隨 經濟發展一直在改變。” } \\
\text { (Hong Kong is changing along with its economic development.) Nevertheless, the said } \\
\text { preposition-structure was placed amid the sentence. Therefore, a score of one was given to the response. }\end{array}$ & $\begin{array}{l}0 \text { structural } \\
1 \text { positional } \\
0 \text { functional }\end{array}$ \\
\hline
\end{tabular}

\begin{tabular}{|c|c|}
\hline $\begin{array}{l}\text { Child's response: } \\
\text { 這小狗已”跟隨 我五年了，現在牠要走了，真的捨不得啊！ }\end{array}$ & \\
\hline $\begin{array}{l}\text { Translation: } \\
\text { This dog }{ }^{*} \text { has been following me for five years. Now it is going to leave, I miss it a lot! }\end{array}$ & \\
\hline $\begin{array}{l}\text { Analysis: } \\
\text { The vocabulary was mistaken as a verb “跟隨” (follow). The verb “跟隨” (follow) belongs to the class of } \\
\text { content words. This mistake led to a wrong response to the syntactic collocation of the preposition “隨 " } \\
\text { (along with). Since the child was unable to exhibit his knowledge of the syntactic collocation of the } \\
\text { vocabulary, a score of } 0 \text { was given to the response. }\end{array}$ & $\begin{array}{l}0 \text { structural } \\
0 \text { positional } \\
0 \text { functional }\end{array}$ \\
\hline
\end{tabular}

Examples of the Scoring for the Syntactic Analysis of the Function Word 
Table 5

\begin{tabular}{l|l|c}
\hline \multicolumn{2}{c}{ Meaning of a Word } \\
\hline \multicolumn{2}{c}{ Denotational Meaning } & Non-denotational Meaning \\
\hline $\begin{array}{l}\text { Intension: the lexeme's defining } \\
\text { properties }\end{array}$ & $\begin{array}{l}\text { Extension:a class of entities the } \\
\text { lexeme denotes }\end{array}$ & Emotive and others \\
\hline
\end{tabular}

Meaning of a Word

Table 6.

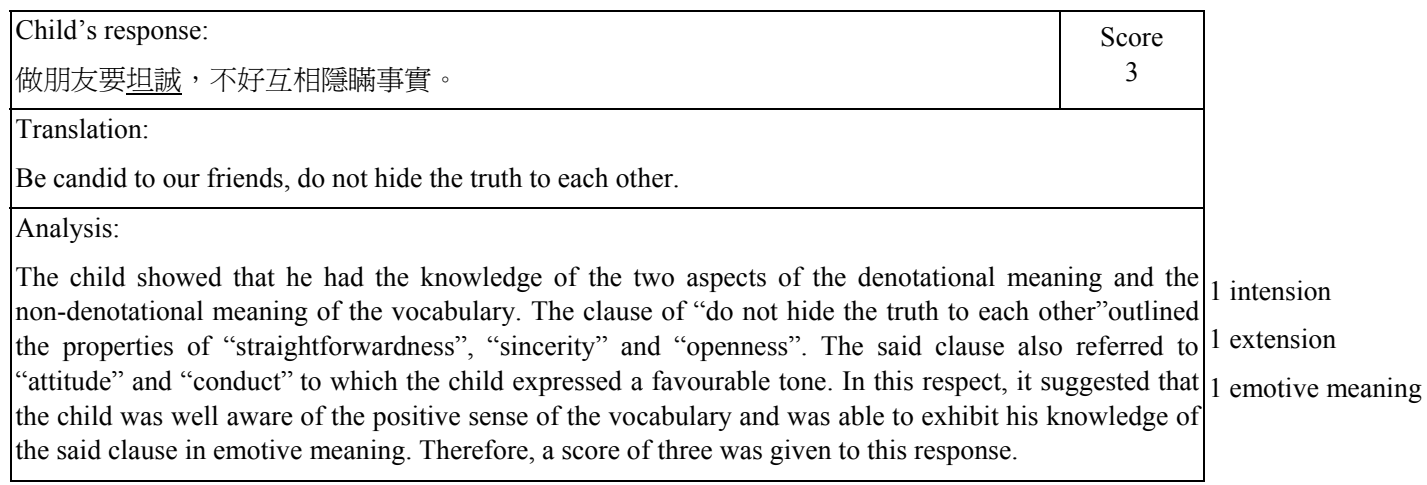

\begin{tabular}{|l|c|}
\hline $\begin{array}{l}\text { Child's response: } \\
\text { 我們不要說謊, 要做個坦誠的孩子。 }\end{array}$ & Score \\
\hline $\begin{array}{l}\text { Translation: } \\
\text { We must not tell lies, must be honest children. }\end{array}$ \\
\hline $\begin{array}{l}\text { Analysis: } \\
\text { The child showed that he had partial knowledge of the denotational meaning of the word. Not to tell lies } \\
\text { and therefore was considered to be trustworthy. The property of "honesty" was clearly expressed in the } \\
\text { clause “must not tell lies". However, the properties of "straightforwardness" and "sincerity" could not be } \\
\text { distinctly identified in the said clause. Since the properties of the vocabulary “坦誠” (candid) was not } \\
\text { sufficiently outlined in the said clause, only a score of two was given to this response for exhibiting the } \\
\text { knowledge of the vocabulary in partial denotational meaning and emotive meaning. }\end{array}$ \\
1 extive meaning \\
\hline
\end{tabular}

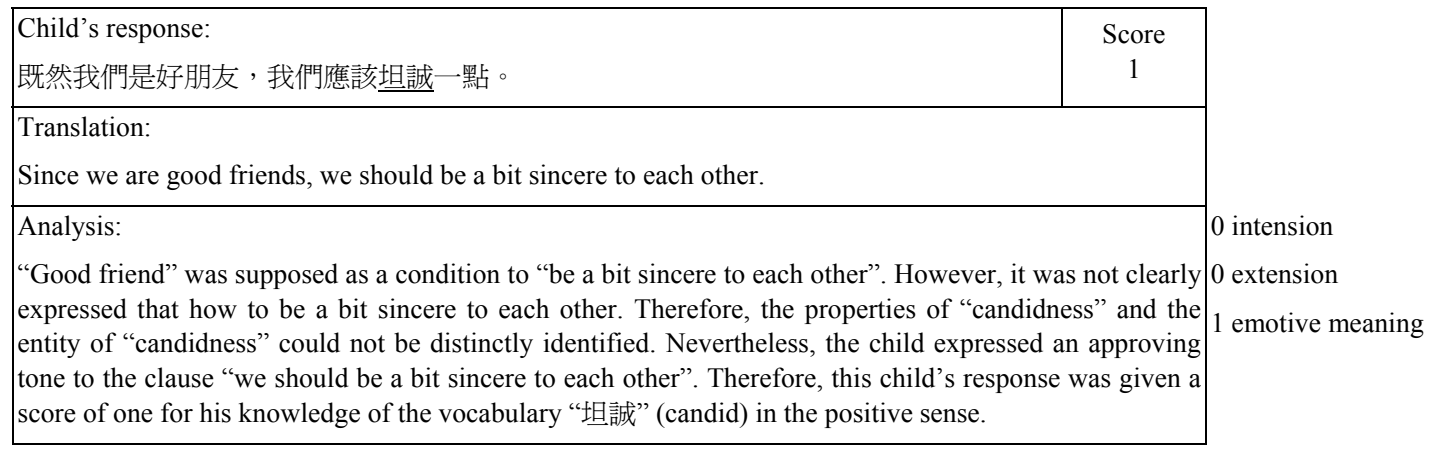

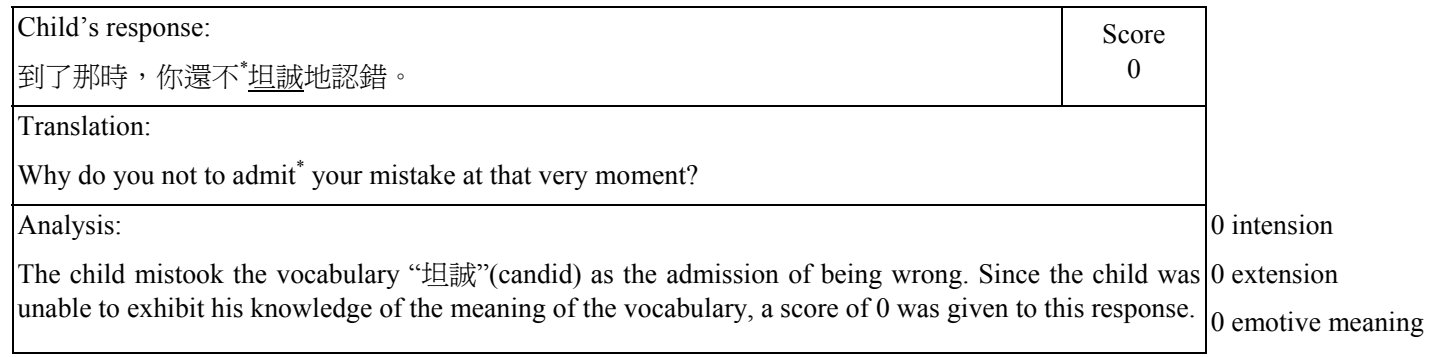


Table 7.

\begin{tabular}{|l|c|}
\hline $\begin{array}{l}\text { Child's response: } \\
\text { 即使你怎樣吵, 我都不會理睬你。 }\end{array}$ & $\begin{array}{c}\text { Score } \\
1\end{array}$ \\
\hline $\begin{array}{l}\text { Translation: } \\
\text { Even though you have made such a loud noise, it will not arouse my attention. }\end{array}$ \\
\hline $\begin{array}{l}\text { Analysis: } \\
\text { The child showed that he had the knowledge of the non-denotational meaning of the }\end{array}$
\end{tabular}

vocabulary. The assumption of "you have made such a loud noise" led to a direct 1 non-denotational response "it will not arouse my attention". A tone expressing "no matter" attached meaning itself closely to these series of events. Since the non-denotational meaning of the vocabulary could be distinctly identified, a score of one was given to the sentence.

\begin{tabular}{|l|c|}
\hline Child's response: & Score \\
*即使你成績優異, 但你的品行卻令人非常討厭。 & 0 \\
\hline
\end{tabular}

Translation:

*Even though your academic achievement is excellent, but your conduct is disgusting.

Analysis:

The child showed that he did not have the knowledge of the meaning of the word. The assumption "your academic achievement is excellent" and the fact "your conduct is disgusting" was not a series of events that was directly related to each 0 non-denotational other. The child's response should be "Even though your academic achievement is meaning excellent, you should not be complacent". The pupil mistook the meaning of the vocabulary “即使”(even though) and was unable to exhibit his knowledge of the vocabulary in non-denotational sense, a score of 0 was given to the sentence.

Examples of the Scoring for the Semantic Analysis of the Function Word

Table 8 .

\begin{tabular}{|c|c|c|c|c|}
\hline Vocabulary data & Scoring & & & \\
\hline Phonological dimension & & & 1 & 0 \\
\hline Orthographical dimension & & 2 & 1 & 0 \\
\hline Syntactic dimension & 3 & 2 & 1 & 0 \\
\hline Semantic dimension (content word) & 3 & 2 & 1 & 0 \\
\hline Semantic dimension(function word) & & & 1 & 0 \\
\hline
\end{tabular}

The Scoring Scheme for the Longitudinal Data 
Table 9.

\begin{tabular}{|c|c|c|c|c|c|c|c|c|}
\hline & \multicolumn{8}{|c|}{ Dimension } \\
\hline & \multicolumn{2}{|c|}{ Phonological } & \multicolumn{2}{|c|}{ Orthographical } & \multicolumn{2}{|c|}{ Syntactic } & \multicolumn{2}{|c|}{ Semantic } \\
\hline & $\begin{array}{l}\text { Year } 4 \\
\text { Mean } \\
(\mathrm{Std}) \%\end{array}$ & $\begin{array}{l}\text { Year } 5 \\
\text { Mean } \\
(\mathrm{Std}) \%\end{array}$ & $\begin{array}{l}\text { Year } 4 \\
\text { Mean } \\
(\mathrm{Std}) \%\end{array}$ & $\begin{array}{l}\text { Year } 5 \\
\text { Mean } \\
(\mathrm{Std}) \%\end{array}$ & $\begin{array}{l}\text { Year } 4 \\
\text { Mean } \\
(\mathrm{Std}) \%\end{array}$ & $\begin{array}{l}\text { Year } 5 \\
\text { Mean } \\
(\mathrm{Std}) \%\end{array}$ & $\begin{array}{l}\text { Year } 4 \\
\text { Mean } \\
(\mathrm{Std}) \%\end{array}$ & $\begin{array}{l}\text { Year } 5 \\
\text { Mean } \\
(\text { Std }) \%\end{array}$ \\
\hline $\begin{array}{l}\text { Content word } \\
\qquad n=20\end{array}$ & $74(15)$ & $82(11)$ & $77(15)$ & $85(11)$ & $69(18)$ & $84(12)$ & $49(17)$ & $69(16)$ \\
\hline $\begin{array}{l}\text { Function word } \\
\qquad \mathrm{n}=15\end{array}$ & $62(23)$ & $83(12)$ & $63(22)$ & $85(10)$ & $45(22)$ & $75(17)$ & $44(23)$ & $68(20)$ \\
\hline $\begin{array}{l}\text { Total } \\
n=35\end{array}$ & $69(19)$ & $83(11)$ & 71(19) & $85(10)$ & $59(23)$ & $80(15)$ & $47(20)$ & $68(17)$ \\
\hline
\end{tabular}

Descriptive Statistics of Percentage Scores in Phonological, Orthographical, Syntactic and Semantic Dimensions for the Vocabulary Items in the Longitudinal Study

Table 10.

\begin{tabular}{|c|c|c|c|c|c|c|}
\hline Source & Measure & $\mathrm{df}$ & Error & $\mathrm{F}$ & $\mathrm{P}$ & $\eta_{p}^{2}$ \\
\hline \multirow[t]{4}{*}{ Year } & Phonological & 1 & 33 & 32.372 & 0.000 & 0.495 \\
\hline & Orthographical & 1 & 33 & 31.820 & 0.000 & 0.491 \\
\hline & Syntactic & 1 & 33 & 79.028 & 0.000 & 0.705 \\
\hline & Semantic & 1 & 33 & 57.138 & 0.000 & 0.634 \\
\hline \multirow{4}{*}{$\begin{array}{c}\text { Year* Class } \\
\text { of Word }\end{array}$} & Phonological & 1 & 33 & 5.330 & 0.027 & 0.139 \\
\hline & Orthographical & 1 & 33 & 6.332 & 0.017 & 0.161 \\
\hline & Syntactic & 1 & 33 & 8.756 & 0.006 & 0.210 \\
\hline & Semantic & 1 & 33 & 0.464 & 0.501 & 0.014 \\
\hline
\end{tabular}

$\eta_{p}^{2}:$ partial eta squared

Within-Subjects Effects of the Univariate Test Results 
Table 11.

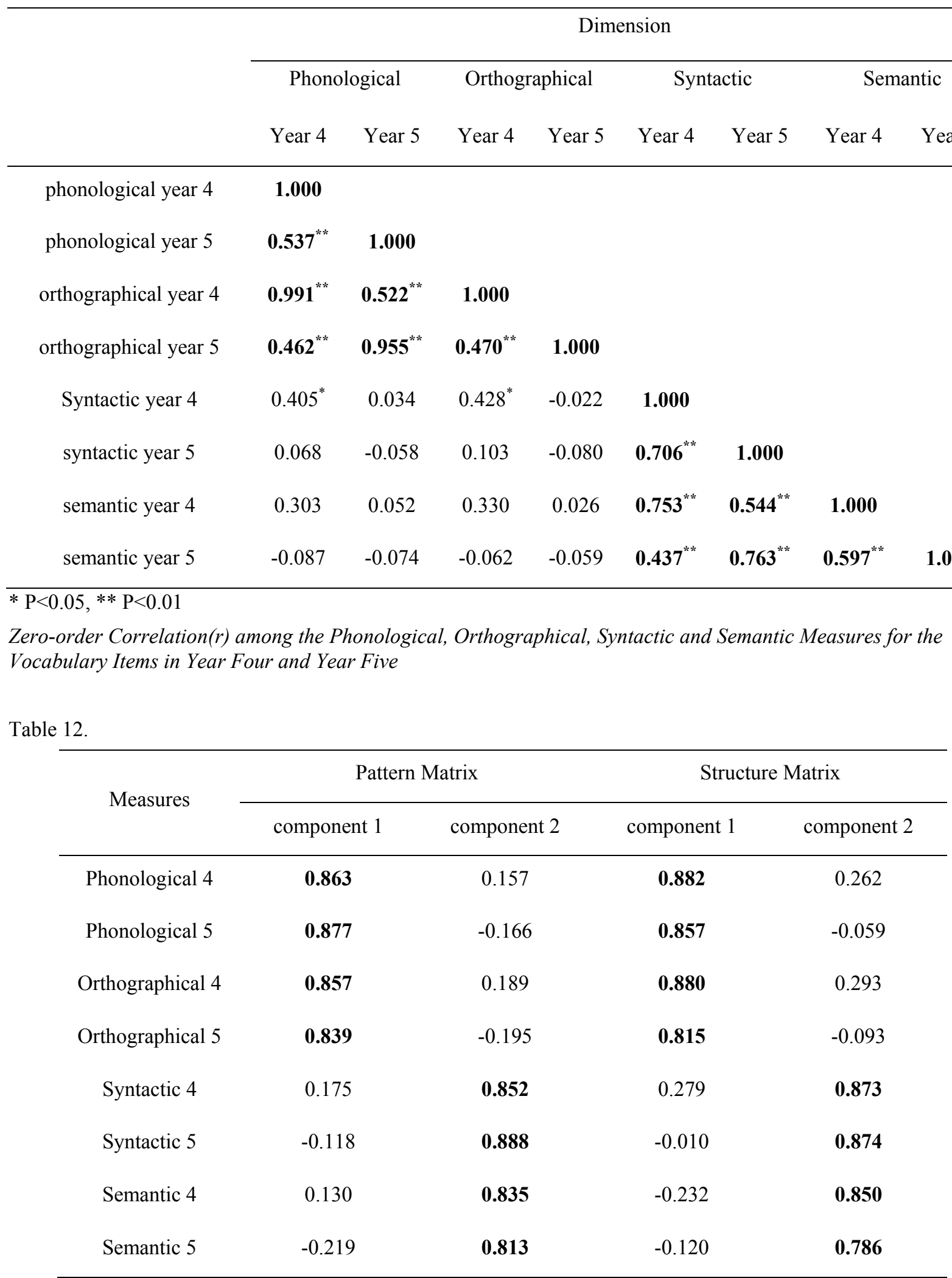

Extraction Method: Principal Component Analysis

Rotation Method: Promax with Kaiser Normalization

Pattern Matrix and Structure Matrix of the Eight Linguistic Measures from the Principal Component Analysis 


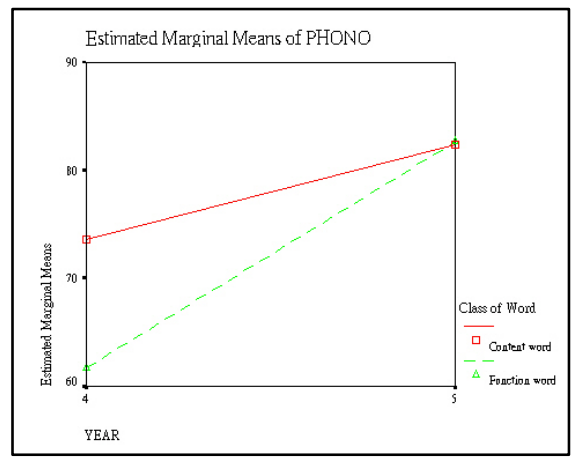

Phonological Measure

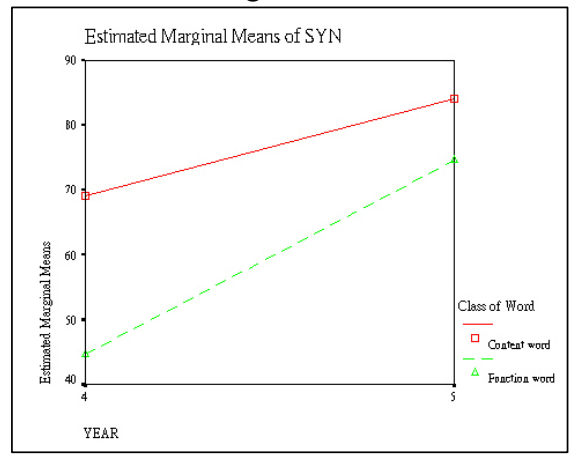

Syntactic Measure

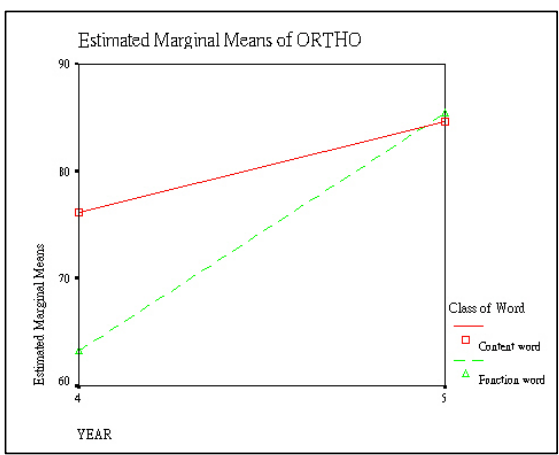

Orthographical Measure

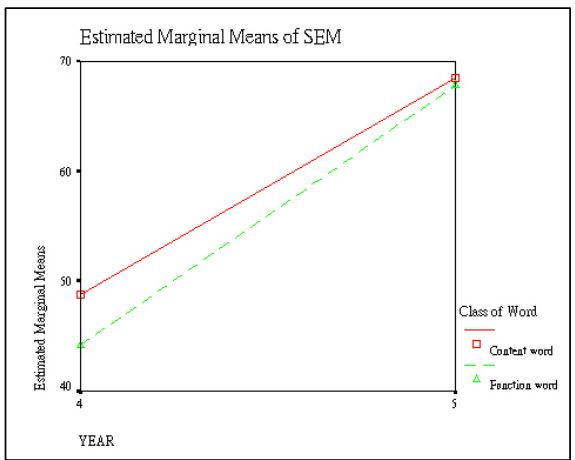

Semantic Measure

Figure 1.

Profiles of the Year* Class of Word Interactions of the Four Linguistic Dimensions

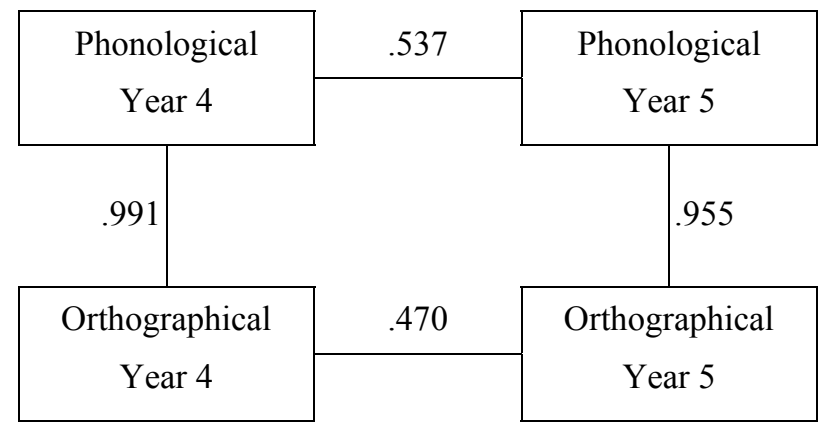

Figure 2.

Correlations between the Phonological Measure and the Orthographical Measure for the Vocabulary Items in Year Four and Year Five

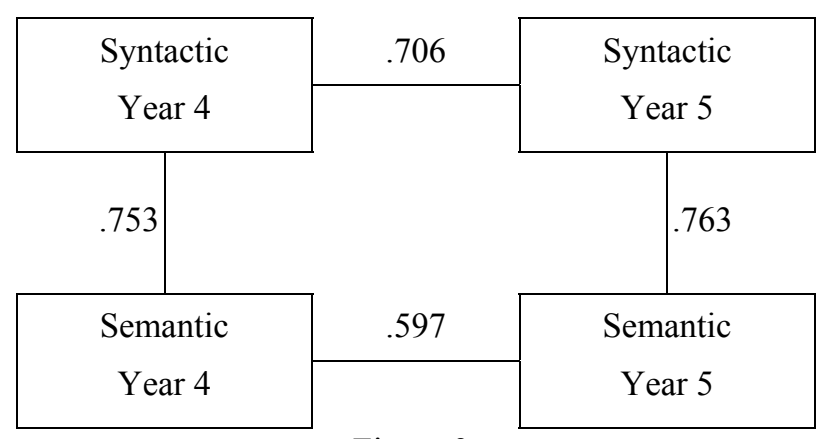

Figure 3.

Correlations between the Syntactic Measure and the Semantic Measure for the Vocabulary Items in Year Four and Year Five 